\title{
Sağlık hizmetleri öğrencilerinin meme kanseri konusunda bilgilerinin değerlendirilmesi
}

\author{
Evaluation of health care students' knowledge on breast cancer
}

\author{
Pelin Palas Karacaำ, Refika Genç Koyucu²®
}

\section{öz}

AMAÇ: Amaç: Araştırma, Sağlık Hizmetleri Meslek Yüksekokulu’nda okuyan öğrencilerin meme kanseri konusunda bilgilerini değerlendirmek amacıyla yapılmıştır.

GEREC VE YÖNTEM: Gereç ve Yöntem: Tanımlayıcı nitelikteki araştırma, 2017-2018 Öğretim yılı/güz yarıyılında Balıkesir Üniversitesi Sağlık Hizmetleri kız öğrencileriyle yürütülmüştür $(\mathrm{N}=117)$. Veriler araştırmacılar tarafından literatürden yararlanılarak hazırlanan, öğrencilerin sosyo-demografik özellikleri ile "Meme Kanseri ve Kendi Kendine Meme Muayenesi Uygulamalarına İlişkin Bilgileri değerlendiren formlar ile değerlendirildi. Elde edilen veriler SPSS 20,0 programı kullanılarak tanımlayıcı veriler, ortalama, standart sapma, sayı ve yüzdelik dağılımları ile gösterilmiştir. Verilerin karşılaştırılmasında ki kare testi kullanılmıştır.

BULGULAR: Öğrencilerin yaş ortalaması 18,85 $\pm 3,6$, menarş yaş ortalaması 13,45 $\pm 1,26$ 'dır. Meme anatomisini bildiklerini ifade eden öğrencilerin oranı \%68,4, meme kanseri ve kendi kendine muayene hakkında bilgi sahibi olduğunu belirten öğrencilerin oranı \%74,4 tür. Araştırmada ögrencilerin, yarıya yakını \%39,3 meme kanseri ile ilgili bilgilerini televizyon, radyo, gazete ve dergilerden aldıklarını belirlendi. Meme kanseri hakkında bilgisi olan öğrencilerin, kendi kendine meme muayenesinin başlama yaşını bilme daha yüksekti $(\mathrm{p}<0,05)$. "Yakın akrabalarında meme kanseri olması meme kanseri riskini arttırıyor, "Kadın olmak meme kanseri riskini arttırıyor", "Bir göğsünde kanser olması diğer göğsünde kanser gelişme riskini arttırıyor" öğrencilerin en çok katıldığı meme risk faktörüne ilişkin ifadelerdir.

SONUÇ: Bu çalışmada öğrencilerin çoğunun meme kanseri hakkında bilgi sahibi oldukları gözükmektedir. Bununla birlikte, kendi kendine meme muayenesi ve önemi ile ilgili bilgileri yetersizdir. Meme kanseri ile ilgili bazı risk faktörlerinin öğrenciler tarafından daha iyi bilindiği görülmektedir.

Anahtar Kelimeler: kendi kendine meme muayenesi, meme kanseri, üniversite öğrencileri, bilgi düzeyi

\section{ABSTRACT}

OBJECTIVE: Aim: The research was conducted to evaluate the knowledge of "Breast cancer" of the students attending health vocational high school.

MATERIAL AND METHODS: Material and Methods: This descriptive study was conducted with female students in the health services department of a university $(\mathrm{n}=117)$. The sociodemographic characteristics of the students and their knowledge about breast cancer were evaluated with the forms developed by the researchers based on the literature. The obtained data are shown with descriptive data, mean, standard deviation, number and percentage distributions using SPSS 20.0 program. Chi square test was used to compare the data.

RESULTS: The mean age of the students was $18.85 \pm 3.6$ and the mean age of menarche was $13.45 \pm 1.26$. The frequency of students who stated that they knew the breast anatomy was $68.4 \%$, and the frequency of students who stated that they had knowledge about breast cancer and self-examination was $74.4 \%$. Nearly half of the students (39.3\%) stated that they obtained their knowledge about breast cancer from television, radio, newspapers and magazines. Students who have knowledge about breast cancer were more likely to know the age of onset of selfexamination $(\mathrm{p}<0.05)$. "Having breast cancer in close relatives increases the risk of breast cancer, "Being a woman increases the risk of breast cancer", "Having a cancer in one breast increases the risk of developing cancer in the other breast" were the statements related to the breast cancer risk factors that students participated most.

CONCLUSION: Most of the students seem to have knowledge about breast cancer. Nevertheless, the frequency of lack of information about breast self-examination and its importance is high. It is seen that some risk factors related to breast cancer are better known by the students. Keywords: breast self examination, breast cancer, university students, level of knowledge
${ }^{1}$ Balıkesir Üniversitesi, Sağlık Bilimleri Fakültesi, Ebelik Anabilim Dalı, Balıkesir, Türkiye 2istinye Üniversitesi, Sağlık Bilimleri Fakültesi, Ebelik Anabilim Dalı, İstanbul, Türkiye

Yazışma Adresi/ Correspondence:

Dr. Öğr. Üyesi Pelin Palas Karaca

Balıkesir Üniversitesi, Sağılı Bilimleri Fakültesi, Balıkesir, Türkiye

Tel: $\quad$ +9050558877 72

E-mail: pelinpalas@hotmail.com

Geliš/ Received: $\quad 11.12 .2020$

Kabul/ Accepted: $\quad 01.05 .2020$

\section{Gíniș}

Kanserin, son yıllarda görülme sıklığının artması nedeniyle; kanser hem dünya hem de ülkemizde önemli bir sağlık sorunudur. Meme kanseri ise, akciğer kanserinden sonra, ikinci sırada yer almakta olup, kansere bağlı en sık ölüm nedenidir. ${ }^{[1,2]}$ Dünya Sağlık Örgütü (WHO, 2019) verilerine göre, gelişmiş ülkelerde kadınlarda meme kanserinin 
görülme sıklığının arttığı ve 2018 yılında yaklaşık 627,000 kadının meme kanserinden öldüğü varsayılmaktadır. ${ }^{[3]}$ Amerika'da da meme kanseri adölesan ve genç kadınlar arasında en sık teşhis edilen invaziv kanser olup, tüm kadınlar arasında yaklaşık \%25 oranında görülmektedir. ${ }^{[4]}$ Ülkemizde ise kadınlar arasında en sık görülen kanser türü meme kanseri olup, ölüme yol açan hastalıklar arasında ise sekizinci sırada gelmektedir. Ülkemizde meme kanseri insidansı 100 binde 40,7 olup, yaklaşık olarak 15,000 kadın meme kanserine yakalanmaktadır. ${ }^{[5]}$ Meme kanserinin insidansı artmış olsa da, erken tanı ve tedavi ile morbidite ve mortalite oranları düşürülmekte, yaşam kalitesi arttırılmaktadır. ${ }^{[6,7]}$ Meme kanseri daha sık 35 yaş ve üzeri kadınlarda görülmesine rağmen, 20-30 yaşlarındaki kadınlarda geç teşhis edilmesi nedeniyle daha kötü prognoza yol açar.

Meme kanseri gelişme riskini genetik, ailesel faktörler, demografik özellikler (yaş, cinsiyet, vb.), reprodüktif öykü (menarş yaşı, doğum yapma yaşı ve sayı, vb.), yaşam tarzı (sedanter yaşam, sigara kullanımı, vb.), çevresel faktörler (alkol kullanımı, sosyo ekonomik düzey, vb.) ve diğer faktörler (Kişisel meme kanseri öyküsü, atipik hiperplazi veya lobüler karsinoma in situ, vücut kitle indeksi) gibi çok sayıda bileşenin etkilemesi nedeni ile etiyolojisi tam olarak bilinmemektedir. ${ }^{[8]}$ Meme kanseri oluşmasını sağlayan birden fazla faktör etkili olduğu için, hastalık gelişiminden korunmak güçtür. Bu bağlamda meme kanserinde mortalite oranlarının azaltılması için erken tanı oldukça önemlidir.

Meme kanseri erken tanısında; Kendine kendine meme muayenesi (KKMM), klinik meme muayenesi (KMM) ve mamografi kullanılan başlıca yöntemlerdir. KKMM 20 yaşında sonra ayda bir kadın tarafından yapılan bir çeşit muayenedir. Ayrıca KKMM, kolay, maliyet gerektirmeyen, mahremiyeti koruyan, invaziv prosedürleri içermeyen ve kadının zamanını almayan bir yöntem olması nedeniyle, diğer erken tarama yöntemlerine göre üstündür. ${ }^{\left[{ }^{-11]}\right.}$

KKMM düzenli olarak yapıldığı zaman kadınlar; kendi memelerini kolayca tanırlar, kendi memesinde ve vücudunda anormal değişikleri erken dönemde tespit edebilirler. ${ }^{[12]}$ Ülkemizdeki meme kanseri vakalarında, memedeki kitlenin büyük bir kısmı ilk olarak kadının kendisi tarafından belirlenmektedir. ${ }^{[13]} \mathrm{Bu}$ nedenle kadınlarda meme kanseri risk faktörleri hakkında bilgilendirmenin yapılması, farkındalığın arttırılması, taramalar konusunda bilinçlendirmemin yapılması, KKMM bilgi düzeylerinin belirlenmesi ve KKMM konusunda maket üzerinde eğitim verilmesi oldukça önemlidir.

Ülkemizde genç yaşta meme kanseri görülme oranı yüksek olduğu için gençlerin meme kanseri, meme kanseri risk faktörleri ve KKMM uygulamaları önemlidir. ${ }^{[14]} \mathrm{Bu}$ bağlamda; çalışmanın amacını sağlık hizmetleri meslek yüksekokulunda okuyan öğrencilerin meme kanseri konusunda bilgilerinin belirlenmesi oluşturmuştur.

\section{YÖNTEM}

\section{Araștırma Soruları}

- Öğrencilerin meme kanseri ve risk faktörleri ile ilgili bilgileri nedir?

- Öğrencilerin KKMM uygulama farkındalıkları nedir?

- Meme kanseri ve KKMM’ne yönelik bilgi alan öğrencilerin, KKMM'ne başlama yaşı, meme kanseri belirtilerine ve risk faktörlerine yönelik görüşleri nedir?

\section{Araștırmanın Tipi}

Araştırma, sağlık hizmetleri meslek yüksekokulunda okuyan öğrencilerin meme kanseri konusunda bilgilerini değerlendirmek amacıyla tanımlayıcı ve prospektif olarak yapılmıştır.

\section{Araștırmanın Yeri ve Zamanı}

Araşıırma, tanımlayıcı tipte olup, 2017-2018 Öğretim yılı/güz yarıyılında döneminde Ekim-Kasım ayları arasında Balıkesir Üniversitesi İvrindi Sağlık Hizmetleri Meslek Yüksekokulu’nda yürütülmüştür.

\section{Araștırmanın Evreni ve Örneklemi}

Araştırmanın evrenini Sağlık Hizmetleri Meslek Yüksekokulu Tibbi Dokümantasyon ve Sekreterlik ile birlikte İlk ve Acil Yardım programında okuyan toplam 287 kız öğrenci oluşturmuştur. Araştırmada örneklem seçimine gidilmeden tüm evrene ulaşılmaya çalışılmış ve 117 öğrenci ile çalışma tamamlanmıştır. Araştırmaya katılmaya gönüllü olmayan, araştırmanın yapıldığı gün okulda olmayan öğrenciler araştırma kapsamına alınmamıştır.

\section{Araștırma Verilerinin Toplanması}

Araştırma verileri iki form ile toplanmıştır. Bu formlardan birinci "Tanıtıcı Bilgi Formu” olup, öğrencilerin yaş, sınıf, bölüm, anne-baba eğitim, ailede meme kanseri öyküsü, medeni ve çalışma durumu gibi sosyo-demografik özellikleri içeren 15 sorudan oluşmaktadır. İkinci form, araştırmacılar tarafından ilgili literatür incelenerek geliştirilen "Meme Kanseri ve Kendi Kendine Meme Muayenesi Uygulamalarına İlişkin Bilgileri Formu" ile toplanmıştır. $\mathrm{Bu}$ form toplam 22 sorudan oluşmaktadır. Bu formda; 
meme kanseri ile ilgili risk faktörlerini, meme kanserinin önlenebilme durumunu, kanserin görülme sıklığını, memenin anatomisini bilme durumunu, meme kanserini bilme durumunu, KKMM bilme, başlama yaşını, temel amacını, el tekniğini, süresini ve uygulandığı zaman aralığını bilme durumlarını inceleyen sorular yer almaktadır.

\section{Araștırmanın Etik Yönü}

Araştırmanın uygulanabilmesi için Sağlık Yüksekokulu Müdürlüğünden kurum izni alınmıştır. Araştırma öncesinde, araştırmacılar tarafından tüm öğrencilere araştırmanın amacı anlatılmış ve soru formları hakkında bilgilendirme yapılmıştır. Araştırmada öğrencilerden soru formunun doldurulması ortalama 15 dakika sürmüştür.

\section{Verilerin Değerlendirilmesi}

Verilerin toplanması ortalama 10-15 dakika sürmüştür. Elde edilen veriler SPSS 20,0 programı kullanılarak tanımlayıcı veriler, ortalama, standart sapma, sayı ve yüzdelik dağılımları ile gösterilmiştir. Verilerin karşılaştırılmasında ki kare testi kullanılmıştır. İstatistiki ölçümlerde anlamlılık değeri 0,05 olarak belirlenmiştir.

\section{Araștırmanın Sınırlılıkları}

$\mathrm{Bu}$ araştırma sadece İvrindi Sağlık Hizmetleri Meslek Yüksekokulu'nda okuyan öğrencilere uygulanmıştır. Bu nedenle sonuçlar genellenemez, sadece araştırmanın yapıldiğı gruba genellenebilir.

\section{BULGULAR}

Araşıırmaya alınan öğrencilerin 117'sinin tanımlayıcı özellikleri Tablo 1'de yer almaktadır. Araştırma kapsamına alınan öğrencilerin yaş ortalaması $18,85 \pm 3,6$, menarş yaş ortalaması ise $13,45 \pm 1,26$ olarak belirlenmiştir. Öğrencilerin \%69,3'ünün sağlık meslek lisesi mezunu, \%73,5'nin ilk ve acil yardım programında okuduğu ve $\% 63,2$ 'sinin ikinci sınıfta öğrenim gördüğü belirlenmiştir. Öğrencilerin tamamına yakın bir kısmının çalısmadığı $(\% 92,3)$ ve bekar $(\% 98,3)$ olduğu saptanmıştır. Öğrencilerin \%87,2'sinin annesi, \%56,4’ünün babası 8 yıl ve altında eğitim almıştır. Öğrencilerin \%29,1'i sigara kullandıklarını bildirmişlerdir. Öğrencilerin \%78,1'nin menstruasyon periyotlarının düzenli olduğu tespit edilmiştir. Öğrencilerin \%5,1'nin meme kanseri tanısı alan yakını olduğu ve bu öğrencilerin \%2,6’sının kız kardeşinde olduğu belirlenmiştir.

Tablo 2'de araştırma kapsamına alınan öğrencilerin meme kanseri ve KKMM ilişkin bilgileri verilmiştir. Tablo 2'ye göre öğrencilerin \%68,4’ü memenin anatomisini bildiğini, \%74,4’ü meme kanseri ve KKMM hakkında bilgi aldığını ve yarısına yakın bir kısmının bu bilgiyi gazete, dergi, radyo ve televizyondan $(\% 39,3)$ öğrendiğini ifade etmişlerdir. Yine öğrencilerin meme kanserinin belirtilerine ilişkin ifadelerine baktığımızda; en sık memede ağrı \%60,7, memede \%95,7 ve koltuk altında ele gelen şişlik \%70,9 görüldüğünü belirtmişlerdir. Araştırmada öğrencilere KKMM temel amacını sorduğumuzda; çok az bir kısmı $(\% 23,9)$ "Kişinin kendi meme dokusunu daha iyi tanıması" cevabını vermiştir. Ayrıca araştırmada öğrencilerin yarısının KKMM başlama yaşını ve uygulama zamanını doğru bildiği belirlenmiştir.

Tablo 1. Öğrencilerin tanımlayıcı özelliklerinin dağılımı

\begin{tabular}{|c|c|c|}
\hline Tanımlayıcı özellikler & \multicolumn{2}{|c|}{$(X \pm S S)$} \\
\hline Yaş ortalaması & \multicolumn{2}{|c|}{$18,85 \pm 3,6$} \\
\hline \multirow[t]{2}{*}{ Menarş ortalaması } & \multicolumn{2}{|c|}{$13,45 \pm 1,26$} \\
\hline & Sayı & $\%$ \\
\hline \multicolumn{3}{|l|}{ En son bitirdiği okul (n: 117) } \\
\hline Düz lise & 14 & 11,9 \\
\hline Sağlık Meslek Lisesi & 81 & 69,3 \\
\hline Mesleki ve Teknik Anadolu Lisesi & 22 & 18,8 \\
\hline \multicolumn{3}{|l|}{ Öğrenim gördüğü program (n: 117) } \\
\hline Illk ve Acil Yardım & 86 & 73,5 \\
\hline Tıbbi Dokümantasyon ve Sekreterlik & 31 & 26,5 \\
\hline \multicolumn{3}{|l|}{ Sinıf } \\
\hline Birinci sınıf & 43 & 36,8 \\
\hline İkinci sınıf & 74 & 63,2 \\
\hline \multicolumn{3}{|l|}{ Medeni Durumu (n: 117) } \\
\hline Evli & 2 & 1,7 \\
\hline Bekar & 115 & 98,3 \\
\hline \multicolumn{3}{|l|}{ Anne Eğitim Durumu } \\
\hline 8 yıl ve alt & 102 & 87,2 \\
\hline 8 yıl ve üstü & 15 & 12,8 \\
\hline \multicolumn{3}{|l|}{ Baba Eğitim Durumu } \\
\hline 8 yıl ve alt & 66 & 56,4 \\
\hline 8yıl ve üstü & 51 & 43,6 \\
\hline \multicolumn{3}{|l|}{ Çalışma durumu (n: 117) } \\
\hline Çalışan & 9 & 7,7 \\
\hline Çalışmayan & 108 & 92,3 \\
\hline \multicolumn{3}{|l|}{ Sigara içme durumu (n: 117) } \\
\hline İçen & 34 & 29,1 \\
\hline İçmeyen & 83 & 70,9 \\
\hline \multicolumn{3}{|l|}{ Menstruasyon düzeni ( $\mathrm{n}: 117)$} \\
\hline Düzenli & 89 & 78,1 \\
\hline Düzensiz & 28 & 21,9 \\
\hline \multicolumn{3}{|c|}{ Meme kanseri tanısı alan yakını ( $\mathrm{n}: 117$ ) } \\
\hline Evet & 6 & 5,1 \\
\hline Hayır & 111 & 94,9 \\
\hline \multicolumn{3}{|c|}{ Meme kanseri tanısı alan yakınlık durumu ( $\mathrm{n}: 6$ ) } \\
\hline Anne & 1 & 0,9 \\
\hline Kız kardeş & 3 & 2,6 \\
\hline Teyze, Hala & 2 & 1,7 \\
\hline
\end{tabular}


Tablo 2. Öğrencilerin meme kanseri ve KKMM hakkındaki bilgi durumlarının dağılımı

\begin{tabular}{lcc}
\hline Meme Kanseri ve KKMM Bilgileri & Sayı & $\%$ \\
\hline Memenin anatomisini bilme (n: 117) & & \\
Evet & 80 & 68,4 \\
Hayır & 37 & 31,6 \\
\hline
\end{tabular}

\section{Meme kanseri ve KKMM bilgi alma \\ durumu (n: 117)}

\begin{tabular}{lll} 
Bilgi aldım & 87 & 74,4 \\
Bilgi almadım & 30 & 25,6 \\
\hline
\end{tabular}

Meme kanseri ve KKMM bilgileri öğrenme yerleri

\begin{tabular}{lcc} 
Gazete-dergi Radyo-Televizyon & 46 & 39,3 \\
Okul & 22 & 18,8 \\
Afiş-Broşür & 8 & 6,8 \\
Sağlık Profesyoneli & 8 & 6,8 \\
Konferans & 3 & 2,6 \\
\hline
\end{tabular}

\section{Meme kanserinin belirtilerine ilişkin ifadeleri*}

Memede ağrı

Memede ele gelen şişlik

Koltuk altnnda ele gelen şişlik

Meme başının içe çekilmesi

Meme başından kanlı akınt

Tek memede sarkıklık

Meme derisinde kuruluk ve buruşukluk

Memede gamzeleşme

Memede yara

Memede sıcaklık hissi

$\begin{array}{ll}71 & 60,7\end{array}$

11295,7

8370,9

$32 \quad 27,4$

$29 \quad 24,8$

$20 \quad 17,1$

$17 \quad 14,5$

$15 \quad 12,8$

$30 \quad 25,6$

$22 \quad 18,8$

KKMM temel amacını bilme ( $\mathrm{n:}$ 117)

Kişinin kendi meme dokusunu daha iyi tanıması $\quad 28 \quad 23,9$

Meme dokusundaki bir kitleyi fark etmesi $\quad 88 \quad 75,2$

Diğer

$\begin{array}{cc}88 & 75,2 \\ 1 & 0,9\end{array}$

\section{KKMM başlama yaşını bilme ( $\mathrm{n}: 117)$}

Doğru bilen

Yanlış bilen

$66 \quad 55$

$51 \quad 45$

KKMM ne zaman uygulandığı tanımlama ( $\mathrm{n}: 117)$

Her hangi bir gün

$45 \quad 38,5$

Ayda bir, Mensturasyon başlamasından

$50 \quad 42,7$

5-7 gün sonra

Diğer (Mensturasyon kanaması başladığında, ilk gün) $22 \quad 18,8$

* Soruya birden fazla yanıt verilmiştir

Meme kanseri ve KKMM'ne yönelik bilgi alan öğrencilerin, KKMM'ne başlama yaşını $(\% 66,7)$ bilme oranlarının; bilgi almayanlara göre yüksek olduğu belirlenmiştir (Tablo 3), ve bu farkın istatistiksel olarak anlamlı olduğu belirlendi $(\mathrm{p}<0,05)$.

Öğrencilerin meme kanseri risk faktörlerine ifadelere katılma durumu incelendiğinde; en çok "Kadın olmak meme kanseri riskini arttırır" (\%85,5), "Yakın akrabada meme kanseri olması meme kanseri riskini arttırır" (\%86,3), "Bir memede kanser olması, diğer memede kanser gelişme riskini arttırır" (\%84,6), "Radyasyona maruz kalma meme kanseri riskini arttırır" $(\% 78,6)$, "İyi huylu meme hastal1ğ geçirme meme kanseri riskini arttırır" (\%56,4), "Sigara kullanma meme kanseri riskini arttırır" $(\% 71,8)$ ifadelerine katıldığı belirlenmiştir (Tablo 4).
Tablo 3. Öğrencilerin meme kanseri ve KKMM bilgi alma durumlarına göre KKMM başlama yaşına ilişkin bilgileri

\begin{tabular}{|c|c|c|c|c|c|}
\hline \multirow{3}{*}{$\begin{array}{l}\text { Meme Kanseri ve } \\
\text { KKMM bilgi alma }\end{array}$} & \multicolumn{5}{|c|}{ KKMM başlama yaşı } \\
\hline & \multicolumn{2}{|c|}{ Doğru Bilen } & \multicolumn{2}{|c|}{ Yanlış Bilen } & \multirow[t]{2}{*}{$\begin{array}{l}\text { Ki-kare } \\
p \text { değeri }\end{array}$} \\
\hline & Sayı & $\%$ & Sayı & $\%$ & \\
\hline Bilgi Alan (n: 87) & 44 & 66,7 & 43 & 84,3 & $X^{2}=4,699$ \\
\hline Bilgi Almayan (n: 30) & 22 & 33,3 & 8 & 15,7 & $\begin{array}{c}P=0,030 \\
P<0,05\end{array}$ \\
\hline
\end{tabular}

Tablo 4. Öğrencilerin meme kanseri risk faktörleri ile ilgili verilen ifadelere katilma durumu

\begin{tabular}{|c|c|c|}
\hline Meme Kanseri Risk Faktörleri Ile Illgili ifadeler & Sayı & Yüzde \\
\hline Kadın olmak meme kanseri riskini arttırır. & 100 & 85,5 \\
\hline $\begin{array}{l}\text { İlk doğumun } 30 \text { yaş üzerinde olması meme } \\
\text { kanseri riskini arttırı. }\end{array}$ & 52 & 44,4 \\
\hline $\begin{array}{l}\text { Illk adetin erken yaşta olması meme kanser } \\
\text { riskini arttırır. }\end{array}$ & 31 & 26,5 \\
\hline $\begin{array}{l}\text { Yakın akrabada meme kanseri olması } \\
\text { meme kanseri riskini arttırır. }\end{array}$ & 101 & 86,3 \\
\hline $\begin{array}{l}\text { İyi huylu meme hastalığı geçirme meme } \\
\text { kanseri riskini arttırır. }\end{array}$ & 66 & 56,4 \\
\hline $\begin{array}{l}\text { Bir memede kanser olması, diğer memede } \\
\text { kanser gelişme riskini arttıır. }\end{array}$ & 99 & 84,6 \\
\hline $\begin{array}{l}\text { Hormon tedavisi görmek meme kanseri } \\
\text { riskini arttırır. }\end{array}$ & 52 & 44,4 \\
\hline $\begin{array}{l}\text { Oral kontraseptif kullanma meme kanseri } \\
\text { riskini arttırır. }\end{array}$ & 47 & 40,2 \\
\hline $\begin{array}{l}\text { Radyasyona maruz kalma meme kanseri } \\
\text { riskini arttrır. }\end{array}$ & 92 & 78,6 \\
\hline $\begin{array}{l}\text { Şişmanlık ve yağlı beslenme meme kanseri } \\
\text { riskini arttırır. }\end{array}$ & 59 & 50,4 \\
\hline Alkol kullanma meme kanseri riskini arttırır. & 66 & 56,4 \\
\hline Sigara kullanma meme kanseri riskini arttrır. & 84 & 71,8 \\
\hline $\begin{array}{l}\text { Bebeğini az emzirme veya emzirmeme meme } \\
\text { kanseri riskinin arttrır. }\end{array}$ & 42 & 35,9 \\
\hline $\begin{array}{l}\text { Hiç doğum yapmamak meme kanseri } \\
\text { riskini arttırır. }\end{array}$ & 16 & 13,7 \\
\hline
\end{tabular}

Öğrencilerin meme kanseri ve KKMM bilgi alma durumlarına göre meme kanserinin risk faktörlerine ilişkin karşılaştırmaları Tablo 5'te görülmektedir. Meme kanseri ve KKMM'ne yönelik bilgi alan öğrencilerin, "bir memede kanserin olması diğer memede kanser gelişme riskini arttırması ( $\mathrm{X}^{2}$ :9,984; $\mathrm{p}$ : 0,002), radyasyona maruz kalınması $\left(X^{2}: 5,620\right.$; p: 0,018)" meme kanseri riskini arttırır ifadelerine katılım sağladıkları ve bu farkın istatiksel olarak anlamlı olduğu görülmüştür. Ayrıca çalışmada meme kanseri ve KKMM yönelik bilgi alan öğrencilerin, "kadın olmak ( $\left.\mathrm{X}^{2}: 0,148 ; \mathrm{p}: 0,700\right)$, ilk doğumu 30 yaş üzerinde yapmış olmak $\left(\mathrm{X}^{2}: 0,504\right.$; $\mathrm{p}$ : $0,478)$, ilk adetin erken yaşta olmak ( $X^{2}: 0,969$; $\left.p: 0,325\right)$, yakın akrabada meme kanseri öyküsü $\left(\mathrm{X}^{2}: 3,188 ; \mathrm{p}: 0,074\right.$, 
Tablo 5. Öğrencilerin meme kanseri ve KKMM bilgi alma durumlarına göre meme kanseri risk faktörlerine ilişkin görüşleri

\begin{tabular}{|c|c|c|c|}
\hline \multirow[t]{2}{*}{ Risk Faktörleri } & \multicolumn{3}{|c|}{$\begin{array}{c}\text { Meme Kanseri ve KKMM Bilgi Alma } \\
\text { Durumları }\end{array}$} \\
\hline & $\begin{array}{c}\text { Hayır } \\
n \%\end{array}$ & $\begin{array}{l}\text { Evet } \\
n \%\end{array}$ & $\begin{array}{c}X^{2} \\
p \text { Değeri }\end{array}$ \\
\hline \multicolumn{4}{|c|}{ Kadın olmak meme kanseri riskini arttırır. } \\
\hline Evet & 2525,0 & 7575,0 & $X^{2}: 0,148$ \\
\hline Hayır & 529,4 & 1270,6 & $\mathrm{p}: 0,700$ \\
\hline \multicolumn{4}{|c|}{ İlk doğumun 30 yaş üzerinde olması meme kanseri riskini arttırır } \\
\hline Evet & 1528,8 & 3771,2 & $X^{2}: 0,504$ \\
\hline Hayır & 1523,1 & 5076,9 & $\mathrm{p}: 0,478$ \\
\hline \multicolumn{4}{|c|}{ illk adetin erken yaşta olması meme kanser riskini arttırır. } \\
\hline Evet & 1032,3 & 2166,7 & $X^{2}: 0,969$ \\
\hline Hayır & 2023,3 & 6676,7 & p: 0,325 \\
\hline \multicolumn{4}{|c|}{ Yakın akrabada meme kanseri olması meme kanseri riskini arttırır. } \\
\hline Evet & 2322,8 & 7877,2 & $X^{2}: 3,188$ \\
\hline Hayır & 743,8 & 956,3 & p: 0,074 \\
\hline \multicolumn{4}{|c|}{ İyi huylu meme hastalığı geçirme meme kanseri riskini arttırır. } \\
\hline Evet & 1522,7 & 5177,3 & $X^{2}: 0,674$ \\
\hline Hayır & 1529,4 & 3670,6 & p: 0,412 \\
\hline \multicolumn{4}{|c|}{ Bir memede kanser olması, diğer memede kanser gelişme riskini arttırır. } \\
\hline Evet & 2020,2 & 7979,8 & $X^{2}: 9,984$ \\
\hline Hayır & 1055,6 & 844,4 & p: 0,002 \\
\hline \multicolumn{4}{|c|}{ Hormon tedavisi görmek meme kanseri riskini arttırır. } \\
\hline Evet & 1528,8 & 3771,2 & $X^{2}: 0,504$ \\
\hline Hayır & 1523,1 & 5076,9 & p: 0,478 \\
\hline \multicolumn{4}{|c|}{ Oral kontraseptif kullanma meme kanseri riskini arttırır } \\
\hline Evet & 1634,0 & 3166,0 & $X^{2}: 2,908$ \\
\hline Hayır & 1420,0 & 5680,0 & p: 0,088 \\
\hline \multicolumn{4}{|c|}{ Radyasyona maruz kalma meme kanseri riskini arttırır. } \\
\hline Evet & 1920,7 & 7379,3 & $X^{2}: 5,620$ \\
\hline Hayır & 1144,0 & 1456,0 & p: 0,018 \\
\hline \multicolumn{4}{|c|}{ Şişmanlık ve yağlı beslenme meme kanseri riskini arttırır. } \\
\hline Evet & 1830,5 & 4169,5 & $X^{2}: 1,479$ \\
\hline Hayır & 1220,7 & 4679,3 & p: 0,224 \\
\hline \multicolumn{4}{|c|}{ Alkol kullanma meme kanseri riskini arttırır. } \\
\hline Evet & 1522,7 & 5177,3 & $X^{2}: 0,674$ \\
\hline Hayır & 1529,4 & 3670,6 & p: 0,412 \\
\hline \multicolumn{4}{|c|}{ Sigara kullanma meme kanseri riskini arttrır. } \\
\hline Evet & 2023,8 & 6476,2 & $X^{2}: 0,524$ \\
\hline Hayır & 1030,3 & 2369,7 & p: 0,469 \\
\hline \multicolumn{4}{|c|}{ Bebeğini az emzirme veya emzirmeme meme kanseri riskinin arttırır. } \\
\hline Evet & 716,7 & 3583,3 & $X^{2}: 2,768$ \\
\hline Hayır & 2330,7 & 5269,3 & p: 0,096 \\
\hline \multicolumn{4}{|c|}{ Hiç doğum yapmamak meme kanseri riskini arttırır. } \\
\hline Evet & 1223,1 & 4076,9 & $X^{2}: 1,079$ \\
\hline Hayır & 1827,7 & 4772,3 & p: 0,570 \\
\hline
\end{tabular}

iyi huylu meme hastalığı geçirme $\left(\mathrm{X}^{2}: 0,674 ; \mathrm{p}: 0,412\right)$, hormon tedavisi görmek ( $\mathrm{X}^{2}: 0,504 ; \mathrm{p}: 0,478$, oral kontraseptif kullanmak ( $\left.\mathrm{X}^{2}: 2,908 ; \mathrm{p}: 0,088\right)$, şişmanlık ve yağlı beslenme ( $\mathrm{X}^{2}: 1,479$; p: 0,224), alkol ( $\left.\mathrm{X}^{2}: 0,674 ; \mathrm{p}: 0,469\right)$, sigara $\left(X^{2}: 0,524, p: 0,412\right)$, bebeğini az emzirme veya emzirmeme ( $\mathrm{X}^{2}: 2,768$; p: 0,096), hiç doğum yapmamak meme kanseri riskini arttırır (X2:2,768; p: 0,096” ifadelerine katıldıkları ve bu farkın anlamlı olmadığı görülmüştür.

Öğrencilerin meme kanseri ve KKMM bilgi alma durumlarına göre meme kanserinin belirtilerine ilişkin karşılaştırmaları Tablo 6'da yer almaktadır. Meme kanseri ve KKMM'ne yönelik bilgi alan öğrencilerin, "tek memede sarkıklık olması (X²:5,391; p: 0,020)" meme kanseri riskini arttırır ifadesine katılım sağladıkları ve bu farkın istatiksel olarak anlamlı olduğu belirlenmiştir. Buna karşılık; me-

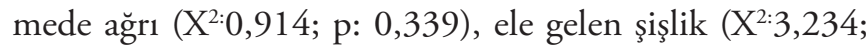
p: 0,72), koltuk altında şişlik $\left(X^{2: 1,132 ; ~ p: ~ 0,287), ~ m e m e ~}\right.$ başının içe çekilme $\left(\mathrm{X}^{2}: 0,009 \mathrm{p}: 0,922\right)$, meme başında kanlı akıntı (X²:0,009; p: 0,922), meme derisinde kuruluk ( $\mathrm{X}^{2}: 0,667$; $\left.\mathrm{p}: 0,414\right)$, memede gamzeleşme $\left(\mathrm{X}^{2}: 3,249\right.$; p: 0,071), memede yara $\left(X^{2}: 3,249 ; \mathrm{p}: 0,071\right)$ ve memede 
Tablo 6. Öğrencilerin meme kanseri ve KКMM bilgi alma durumlarına göre meme kanserinin belirtilerine ilişkin ifadeleri

\begin{tabular}{|c|c|c|c|}
\hline \multicolumn{4}{|c|}{ Meme Kanseri ve KKMM Bilgi Alma } \\
\hline Meme Kansereinin Belirtilerine Ilişkin ifadeler & $\begin{array}{c}\text { Hayır } \\
n \%\end{array}$ & $\begin{array}{c}\text { Evet } \\
n \%\end{array}$ & $\begin{array}{c}X^{2} \\
p \text { Değeri }\end{array}$ \\
\hline \multicolumn{4}{|l|}{ Memede ağrı } \\
\hline Evet & 1622,5 & 5577,5 & $X^{2}: 0,914$ \\
\hline Hayır & 1430,4 & 3269,6 & p: 0,339 \\
\hline \multicolumn{4}{|l|}{ Memede ele gelen şişlik } \\
\hline Evet & 2724,1 & 8575,9 & $X^{2}: 3,234$ \\
\hline Hayır & 360,0 & 240,0 & p: 0,72 \\
\hline \multicolumn{4}{|l|}{ Koltuk altında ele gelen şişlik } \\
\hline Evet & 1922,9 & 6477,1 & $X^{2}: 1,132$ \\
\hline Hayır & 1132,4 & 2367,6 & p: 0,287 \\
\hline \multicolumn{4}{|l|}{ Meme başının içe çekilmesi } \\
\hline Evet & 825,0 & 2475,0 & $X^{2}: 0,009$ \\
\hline Hayır & 2225,9 & 6374,1 & p: 0,922 \\
\hline \multicolumn{4}{|l|}{ Meme başından kanlı akıntı } \\
\hline Evet & 413,8 & 2586,2 & $X^{2}: 0,009$ \\
\hline Hayır & 2629,5 & 6270,5 & p: 0,922 \\
\hline \multicolumn{4}{|l|}{ Tek memede sarkıklık } \\
\hline Evet & 15,0 & 1995,0 & $X^{2}: 5,391$ \\
\hline Hayır & 2929,9 & 6870,1 & p: 0,020 \\
\hline \multicolumn{4}{|l|}{ Meme derisinde kuruluk ve buruşukluk } \\
\hline Evet & 317,6 & 1482,4 & $X^{2}: 0,667$ \\
\hline Hayır & 2727,0 & 7373,0 & p: 0,414 \\
\hline \multicolumn{4}{|l|}{ Memede gamzeleşme } \\
\hline Evet & 16,7 & 1493,3 & $X^{2}: 3,249$ \\
\hline Hayır & 2928,4 & 7371,6 & $\mathrm{p}: 0,071$ \\
\hline \multicolumn{4}{|l|}{ Memede yara } \\
\hline Evet & 516,7 & 2583,3 & $X^{2}: 3,249$ \\
\hline Hayır & 2528,7 & 6271,3 & $\mathrm{p}: 0,071$ \\
\hline \multicolumn{4}{|l|}{ Memede sıcaklık hissi } \\
\hline Evet & 940,9 & 1359,1 & $x^{2}: 3,313$ \\
\hline Hayır & 2122,1 & 7477,9 & $\mathrm{p}: 0,069$ \\
\hline
\end{tabular}

sicaklık hissi ( $\mathrm{X}^{2}: 3,313$; p: 0,069) ile meme kanseri ve KKMM bilgi alma arasında istatistiksel olarak anlamlı fark bulunmamıştır.

\section{TARTIȘMA}

Meme kanseri, genç yaştaki kadınlarda kitlenenin daha geç belirlenmesi nedeniyle prognozun daha kötü olduğu bildirilmektedir. ${ }^{[15,16]} \mathrm{Bu}$ nedenle araştırma öğrencilerin meme kanseri konusunda bilgilerini değerlendirmek ve farkındalık yaratmak için 117 kız öğrenciye uygulanmıştır. Öğrencilerin büyük bir kısmının sağlık meslek lisesinden mezun oldukları, ilk ve acil yardım bölümde öğrenim gördükleri, çalışmadıkları ve bekar oldukları belirlenmiştir.

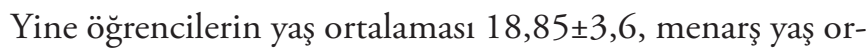
talaması ise 13,45 1,26 olarak bulunmuştur. KKMM ile ilgili hemşirelik öğrencileri üzerinde yapılan bir çalışmada; bizim araştırmamıza benzer bir şekilde öğrencilerinin ortalama yaş ortalaması $20,86 \pm 1,99$, menarş yaş ortalaması ise $13,29 \pm 1,20$ olarak belirlenmiştir. ${ }^{[17]} \mathrm{K}$ ız öğrenciler üzerinde yapılan bir diğer bir çalışmada katılımcıların, yaş

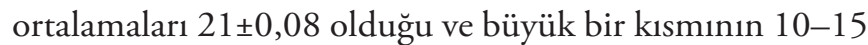
yaş arası ilk adetini gördüğü saptanmıştır. ${ }^{[15]}$ Diğer bir çalışmada ise öğrencilerin yaş ortalaması 18,99 $\pm 1,53$ olarak tespit edilmiştir. ${ }^{[1]}$ Çalışmamızın yaş ve menarş ortalaması diğer üniversite öğrencileri ile yapılan çalışma sonuçları ile benzerdir.

Araştırmada en sık öğrencilerin birinci derece yakınında $(\% 5,1)$ meme kanseri öyküsü bulunmaktadır. Yapılan bir çalışmada da benzer bir şekilde birinci derece akrabalarında \%7,5 meme kanseri öyküsü bulunmuştur. ${ }^{[16]}$ Üniversite Öğrencilerinin Meme ve Serviks Kanseri Farkındalığı: İki Ülke ve İki Farklı Kültürün Karşılaştırılması başlıklı diğer bir araştırmada Türk öğrencilerin \%12,6'sı ve Polonyalı öğrencilerin $\% 18,1$ 'inin ailelerinde meme kanseri öyküsünün olduğu belirlenmiştir. ${ }^{[18]} \mathrm{Bu}$ araştırmanın sonuçları literatürdeki araştırma sonuçları ile benzerdir.

Meme kanserinde sigara kullanımı ile ilgili yapılan çalışmalar, sigaranın meme kanserine yakalanma riskini arttırdığını göstermektedir. ${ }^{[13,15]}$ Araştırmada öğrencilerin büyük bir kısmının sigara kullanmadığını ve sigaranın meme kanseri 
riskini arttırdığı görüşünü destekledikleri belirlenmiştir. Araştırmada, meme kanseri risk faktörleri arasında önemli bir yere sahip olan sigaranın, öğrencilerin büyük bir kısmı tarafından bilinmesi sevindirici bir bulgu olsa da; sigaranın bırakılması ile ilgili müdahale eğitimlerinin düzenli aralıkla tekrar edilmesi önerilir.

Araştırmada öğrencilerin yarısından fazlasının meme kanseri ve KKMM hakkında bilgi sahibi olduklarını ifade etmişlerdir. Erbil ve Bölükbaş่ının ${ }^{[17]}$ yaptıkları çalışmada büyük bir kısmının meme kanseri hakkında bilgi sahibi olduklarını bildirmiştir. Yapılan diğer çalışmalarda da bu bulgumuzu destekler şekilde meme kanseri hakkında öğrencilerin ve kadınların bilgi sahibi oldukları belirlenmiştir. ${ }^{[19-22]} \mathrm{Bu}$ çalışmadan farklı olarak öğrencilerin sadece çok az bir kısmının meme kanseri ve KKMM hakkında bilgi sahibi olduğunu gösteren çalışmalar da mevcuttur. ${ }^{[23,24]}$ Çalışmanın bu sonucu, öğrencilerin KKMM bilgi aldığı ancak, bu bilgilerin güçlendirilmesi ve eğitim programları ile daha çok öğrencinin farkındalığının arttırılması gerektiği şeklinde yorumlanabilir.

Meme Kanseri ve KKMM ile ilgili bilgiyi nereden aldınız?" sorusuna verdikleri cevapta, öğrencilerin yarısına yakını gazete-dergi, radyo ve televizyondan öğrendiklerini belirtmiştir. Literatürde bu konu ile ilgili yapılan çalışmalarda da kadınların yarısına yakın bir kısmı KKMM ile ilgili bilgiyi görsel basından aldıklarını ifade etmişlerdir. ${ }^{[25-28]}$ Ayrıca araştırmada, meme kanseri ve KKMM ile ilgili sağlık profesyonellerinden bilgi aldığını ifade eden öğrenci oranının çok düşük olduğu dikkati çekmektedir. Literatürde de çeşitli çalışmaların sonuçlarının bulgularımız ile paralellik gösterdiği görülmektedir. Bu durum kadınlarda sık görülen meme kanserine yönelik bilgilendirmede medyanın da önemli rolleri olduğunu göstermektedir. Ayrıca sağlık hizmetlerinde okuyan öğrencilere yönelik meme kanseri belirtilerine, risk faktörlerine ve tarama programlarına yönelik bilgilerin eğitim müfredatının içeriğin geliştirilerek eklenmesi ve seminer/konferans programları düzenlenerek arttırılmasına gereksinim olduğu söylenebilir.

Araştırmada öğrenciler, meme kanserinin belirtilerine ilişkin en sık meme ve koltuk altında ele gelen şişlik ve ağrı olduğunu ifade etmişlerdir. Benzer şekilde Güzel ve Bayraktar'ın (2019) ${ }^{[29]}$ çalışmasında kadınların en fazla memede kitleyi ifade ettikleri bulunmuştur. Yapılan bir diğer çalışmada ise genç kadınların \%83,4'ü meme kanseri belirtileri arasında ele gelen bir şişlik olduğunu ifade etmişlerdir. ${ }^{[30]} \mathrm{Bu}$ araştırmada öğrencilerin, meme kanseri belirtilerine ilişkin bilgilerinde eksik noktaların bulundugu ve bilgilerinin arttırılması konusunda eğitime ihtiyaçları olduğu söylenebilir.
KKMM meme sağlığının geliştirilmesinde ve kişinin kendi meme dokusunu tanımasında etkili bir yöntemdir. ${ }^{[24]} \mathrm{Bu}$ doğrultuda yaptığımız araştırmada öğrenciler, KKMM'nin amacına ilişkin az bir kısmı $(\% 23,9)$ oranında "Kişinin kendi meme dokusunu daha iyi tanıması" görüşünü katıldıkları belirlenmiştir. Bu sonuç, öğrencilerin büyük bir kısmının meme kanseri ve KKMM ile ilgili bilgi almasına karşın; KKMM temel amacının bilme düzeylerinin ve farkındalığının yeterli olmadığını düşündürmektedir.

KKMM 20 yaşından sonra her kadın tarafından kolayca evinde yapılabilecek, erken tanıya yönlendirebilecek ve ucuz bir yöntem dir. ${ }^{[31]}$ Araştırmamızda meme kanseri ve KKMM bilgi alan öğrencilerin; KKMM'yi başlama yaşını bilme oranlarının konuya ilişkin bilgi almayan öğrencilere göre daha yüksek olduğu saptandı $(\mathrm{p}<0,05)$. Bu bulgu bilgi alan öğrencilerin KKMM başlama yaşını bilme durumlarını etkilediğini göstermektedir. Bu nedenle gençlere yönelik, sağlık profesyonelleri tarafindan meme kanseri ve KKMM konusunda bilgi düzeylerinin arttırılması amacıyla eğitimlerin ve seminerlerin düzenlenmesi gerektiği kanısındayız.

Dünyanın hemen her bölgesinde önemli bir sağlık sorunu olan meme kanseri, kadınlar arasında en yaygın kanser türüdür. ${ }^{[18]}$ Araştırmada, öğrencilerin büyük bir kısmının kadın olmanın meme kanseri riskini arttırdığını ifade etmişlerdir. Yakın akrabada (anne, kız kardeş) meme kanseri olması kişide, meme kanseri görülme riskini arttırmaktadır (yüksek derecede risk faktörü). ${ }^{[32]}$ Araştırmada öğrenciler "Yakın akrabada meme kanseri olmasi meme kanseri riskini arttırır" ifadesine \%86,3 oranında katılım sağlamıştır. Kız öğrencilerin meme kanseri ve KKMM bilgilerinin incelendiği bir çalışmada, bizim çalışma sonucumuzu destekler şekilde, katılımcıların büyük bir kısmı yakın akrabada meme kanserinin olması kanser riskini arttırdığını belirtmişlerdir. [15] Çalışmamızda, öğrencilerin tamamına yakınının ailede meme kanseri durumlarına ilişkin farkındalıklarının yüksek olduğu belirlenmiştir.

Bir memede meme kanserinin olması, diğer memede meme kanseri riskini arttırmaktadır (Yüksek/artmış risk). [32] Araştırma öğrencilerin büyük bir kısmı "Bir memede kanser olması, diğer memede kanser gelişme riskini artturtr" ifadesine katılmışlardır. Çalışma bulgumuzu destekler şekilde, yapılan bir çalışmada kız öğrencilerin yarısından fazlası memede kitlenin riski artırı ı̆̆ını bildirmişlerdir.

Meme kanserinin bazı risk faktörleri değiştirilemezken, obezite ve sedanter yaşam gibi bazı risk faktörleri kolayca değiştirilebilir. ${ }^{[18]}$ Çalışmada "Şişmanlık ve yağlı beslenme meme kanseri riskini artturt?" ifadesine öğrencilerin yaklaşık yarısının katıldığı belirlenmiştir. Bu sonuca göre öğrencilerin meme kanserine ilişkin bilgilerinde eksik olan 
noktaların bulunduğu, kanserden korunmaya yönelik farkındalığın arttırılması ve sağ lıklı yaşam biçimlerinin öğrencilere kazandırılması gerektiği söylenebilir.

Meme kanseri risk faktörleri arasında olan "Alkol kullanımı meme kanseri riskini arttırır" ifadesine öğrencilerin büyük bir kısmı katılım sağlamışıı. Bu konu ile ilgili yapılan bir çalışmada, araştırma bulgumuzu destekler şekilde "Alkol kullanmak meme kanseri riskini artırır" ifadesine öğrencilerin yarısından fazlası katılım sağlamıştır. ${ }^{[15]}$ Çalışmamızda öğrencilerin alkol kullanmanın meme kanseri riski oluşturabileceği durumlarına ilişkin farkındalıklarının olduğu belirlenmiştir.

Araştırmada meme kanserinde risk faktörü olarak belirlenen "Bebeğini az emzirme veya emzirmeme meme kanseri riskinin arttırı, hiç doğum yapmamak meme kanseri riskini artturır, ilk adetin erken yaşta olması meme kanser riskini arttırır" ifadelerine daha az sayıda öğrencinin katıldığı saptanmıştır. Bu sonuçlara göre öğrencilerin meme kanseri risk faktörlerine yönelik bilgilerinin eksik olmasından kaynaklandığı söylenebilir.

Araştırmamızda meme kanseri ve KKMM'ye yönelik bilgi alan öğrencilerin; "tek memede sarkıklık olması meme kanserinin belirtileri arasındadır" bilme oranlarının bilgi almayan öğrencilere göre daha yüksek olduğu saptandı. Kolutek ve Aydın Avcı'nın çalışmasında da (2015) kadınların eğitim öncesinde meme kanserinin belirtilerini, bilmediği; kadınlara verilen eğitim bilgi düzeylerinin yüksekliği belirlenmiştir. ${ }^{[33]}$ Diğer bir çalışmada ise; meme kanserinin erken tanısına yönelik bilgi alan kadınların; meme kanserinde risk faktörlerini bilme oranlarının, bilgi almayan kadınlara göre daha yüksek olduğu tespit edilmiştir. ${ }^{[29]} \mathrm{Bu}$ sonuç, meme kanserine yönelik verilen eğitimlerin, bireylerin farkındalıklarını arttırdığını göstermektedir.

\section{SONUÇ VE ÖNERILER}

Bu çalışmada öğrencilerin çoğunluğunun daha önce meme kanseri ve KKMM ile ilgili bilgi aldığı, buna rağmen ne zaman uygulanması gerektiğini ve temel amacını bilmeyen öğrencilerin yüksek olduğu, en çok kadın akrabada meme kanseri öyküsü, bir memede kanser öyküsü, radyasyona maruz kalma, iyi huylu meme hastalığı geç ve yakın akrabada meme kanseri öyküsü meme kanseri riskini arttırdığını düşündükleri belirlenmiştir.

\section{Araşttrmadan elde edilen sonuçlar doğrultusunda:}

- Öğrencilerin meme kanseri ve KKMM yönelik farkındalıklarının geliştirilmesi (seminer, konferans, sosyal ve görsel medya),
- Öğrencilerinin kendi sağlığı ile ilgili becerilerinin geliştirmelerinin sağlanması,

- Öğrencilerin meme kanseri ve KKMM ile ilgili düzenlenen etkinliklere katılımının sağlanması, tutum ve davranışlarda değişim göstermelerinin takip edilmesi,

- Bu konu ile ilgili nicel, nitel ve deneysel çalışmalarının yapılması önerilebilir.

\section{Hakem Değerlendirmesi}

Dış bağımsız

Çıkar Çatışması

Yazarlar çıkar ilişkisi olmadığını beyan etmişlerdir.

Finansal Destek

Herhangi bir mali destek alınmamıştır.

\section{Peer-review}

Externally peer-reviewed.

Conflict of Interest

No conflict of interest was declared by the authors.

Financial Disclosure

No financial disclosure was received.

\section{KAYNAKLAR}

1. Höbek Akarsu R, Yüzer Alsaç S. Hemşirelik öğrencilerinin Kendi Kendine Meme Muayenesi (KKMM) bilme ve uygulama durumlarının belirlenmesi. Bozok Tip Derg 2019;9:115-21. [CrossRef]

2. National Center for Health Statistics Staff. Health, U. S. with Urban and Rural Health Chartbook, 2001. Hyattsville, Md: National Center for Health Statistics, 2001. https:/www.cdc.gov/ nchs/data/hus/hus01cht.pdf

3. World Health Organization. Breast Cancer. https:/www.who.int/ cancer/prevention/diagnosis-screening/breast-cancer/en/

4. Ademuyiwa FO, Gao F, Hao L, Morgensztern D, Aft RL, Ma CX, Ellis MJ. US breast cancer mortality trends in young women according to race. Cancer 2015;121:1469-76. [CrossRef]

5. Özkan S, Keskinkılıç B, Gültekin M, Karaca AS, Öztürk C, Boztaş G, et al. Ulusal Kanser Kontrol Planı 2013-2018. TC. Sağlık Bakanlığı Türkiye Halk Sağlığı Kurumu Yayınları, Ankara: 2018. p.18-56.

6. Gençtürk N, Demirezen E, Ay F. Health beliefs of midwifery students at Istanbul University about breast cancer and breast selfexamination acknowledgements. J Cancer Educ 2017;32:784-9. [CrossRef]

7. Kirag N, Kızılkaya M. Application of the Champion Health Belief Model to determine beliefs and behaviors of Turkish women academicians regarding breast cancer screening: A cross sectional descriptive study. BMC Womens Health 19 6;19:132. [CrossRef]

8. Koçak S, Çelik L, Özbaş S, Dizbay S, Tükün A, Yalçın B. Meme kanserinde risk faktörleri, riskin değerlendirilmesi ve prevensiyon: 2010 Konsensus Raporu. J Breast Health 2011;7:47-67. http://thejournalofbreasthealth.com/content/files/sayilar/23/ buyuk/2541.pdf

9. Boxwala FI, Bridgemohan A, Griffith DM, Soliman AS. Factors associated with breast cancer screening in Asian Indian women in Metro-Detroit. J Immigr Minor Health 2010;12:534-43. [CrossRef]

10. Husna PH, Marni, Nurtanti S, Handayani S, Ratnasari NY, Ambarwati R, Susanto T. Breast self-examination education for skill and behavior. Educ Health (Abingdon) 2019;32:101-2. [CrossRef] 
11. Beydağ KD, Yürügen $\mathrm{B}$,. The effect of Breast Self-Examination Education Given to midwifery students on their knowledge and attitudes. Asian Pac J Cancer Prev 2010;11:1761-4.

12. Birhane N, Mamo A, Girma E, Asfaw S. Predictors of breast self examination among female teachers in Ethiopia using health belief model. Arch Public Health 2015;27;73:39. [CrossRef]

13. Aydoğdu SGM, Karapelit Z. Ebelik öğrencilerinin kendi kendine meme muayenesi ile ilgili bilgi ve tutumlarının belirlenmesi. Androl Bul 2017;19:78-85. [CrossRef]

14. Özçelik F. Türk Cerrahi Derneği Yeterlilik Okulu Ders Notlar1. https:/www.turkcer.org.tr/files/ publications/93/92df9b069dd3392e431da026cb3701e7. pdf\#page=308 Ankara 2018.

15. Alpteker H, Gümüş D, Doğan S, Bilir S, Önal M. Kız öğrencilerin meme kanseri ve kendi kendine meme muayenesi bilgi ve uygulamalarının incelenmesi. J Breast Health 2011;7:176-81.

16. Canbulat N. Sağlık çalışanlarının meme kanseri, kendi kendine meme muayenesi ve mamografiye ilişkin sağlık inançlarının incelenmesi (Yüksek lisans tezi). Atatürk Üniversitesi Cerrahi Hastalıklar Hemşireliği Anabilim Dalı, Erzurum; 2006.

17. Erbil N, Bölükbaş N. Health beliefs and breast selfexamination among female university nursing students in Turkey. Asian Pac J Cancer Prev 2014;15:6525-29. [CrossRef]

18. Koc G, Gulen-Savas H, Ergol S, Yildirim-Cetinkaya M, Aydin $\mathrm{N}$. Female university students' knowledge and practice of breast self-examination in Turkey. Niger J Clin Pract 2019;22:410-5. [CrossRef]

19. Kabataş MS, Kızıl H, Duman D. Bayan öğretmenlerin meme kanseri ve kendi kendine meme muayenesi hakkında bilgi, tutum ve davranışlarının incelenmesi. J Breast Health 2010;6:150-5. https://www.eurjbreasthealth.com/content/files/sayilar/21/ buyuk/2251.pdf

20. Şen S, Başar F. Kütahya bölgesinde yaşayan kadınların kendi kendine meme muayenesi ve meme kanseri ile ilgili bilgi düzeyleri. J Breast Health 2012;8:185-90.

21. Ameer K, Abdulie S, Pal S, Arebo K, Kassa G. Breast cancer awareness and practice of breast self-examination among female medical students in Haramaya University, Harar, Ethiopia. IJIMS 2014;2:109-19.

22. Akpo EE, Akpo MO, Akhator A. Breast cancer knowledge and screening practices among Nigerian medical students. ISPUB Internet J Health 2010;11:8. https://print.ispub.com/api/0/ispubarticle/5445
23. Türkmen H. Üniversite Öğrencilerinin Kendi Kendine Meme Muayenesini Bilme ve Uygulama Durumları. Manisa Celal Bayar Sağlık Bilimleri Enstitüsü Derg 2017;4:586-92. http://static.dergipark.org.tr/article-download/3495/cac1/ ab69/59558e84e4f5d.pdf?

24. Gümüş Şekerci Y, Sohbet R. Meme Kanseri ve Erken Tanı Yöntemleri Eğitiminin Öğrencilerin Sağlık Bilgisi, İnanç ve Uygulamalarına Etkisi. JAREN 2019;5:204-12. [CrossRef]

25. Kılıç S, Uçar M, Seymen E, İnce S, Ergüvenli Ö, Yıldırım A, et al. Kendi kendine meme muayenesi bilgi ve uygulamasının GATA Eğitim Hastanesinde görevli hemşire, hemşirelik öğrencileri ve hastaneye müracaat eden kadın hastalarda araştırılması. Gülhane Tip Derg 2006;48:200-4. http://cms.galenos.com.tr/Uploads/ Article_33061/GMJ-48-200-En.pdf

26. Çevik C, Akbulut G, Erkal S. Memede kitle şüphesiyle hastaneye başvuran kadınların kendi kendine meme muayenesi hakkındaki bilgi düzeylerinin kitle fark edilmesine etkisi. Hemşirelik Forumu Derg 2005;6:4-8.

27. Atlı Ö, Yenerenoğlu H. Kadınlara meme kanseri ve kendi kendine meme muayenesi hakkında verilen eğitimin bilgi düzeylerine etkisinin incelenmesi. Ege Üniversitesi Hemşirelik Yüksekokulu 5. Ulusal Hemşirelik Öğrencileri Kongresi Kitabı, 2005. s.54.

28. Karayurt Ö, Coşkun, A, Cerit K. Hemşirelerin meme kanseri ve kendi kendine meme muayenesine ilişkin inançlanı ve uygulama durumu. J Breast Health 2008;4:16-20. https://www. eurjbreasthealth.com/content/files/sayilar/11/buyuk/991.pdf

29. Güzel N, Bayraktar N. Kadınların meme kanseri erken tanısına yönelik farkındalıklarının ve uygulamalarının belirlenmesi. Hacettepe Üniversitesi Hemşirelik Fakültesi Derg 2019;6:101-11. http://static.dergipark.org.tr/article-download/2edf/6c20/2103/5 d4018000cd51.pdf?

30. Özen B, Zincir H, Kaya Erten Z, Özkan F, Elmalı F. Knowledge and Attitudes of Women about Breast Cancer, Self Breast Examination and Healthy Life Style Behaviours. J Breast Health 2013;9:200-4. [CrossRef]

31. Franek GA, Nowak-Kaputsa ZE, Cabaj M. Breast cancer prophylaxis among nurses. Wiad Lek 2004;57:82-4. https:// pubmed.ncbi.nlm.nih.gov/15884211/

32. Güllüoğlu BM. Meme hastalıklarına yaklaşım: Meme kanseri için risk değerlendirmesi ve tarama stratejileri. Türk Aile Hek Derg 2008;12:9-17. [CrossRef]

33. Kolutek R, Aydın Avcı İ. Eğitim ve evde izlemin, evli kadınların meme ve serviks kanseri ile ilgili bilgi düzeylerine ve uygulamalarına etkisi. J Breast Health 2015;11:155-62. [CrossRef] 